Dedicated to the blessed memory of A.F. Prikhotko,

https://doi.org/10.15407/ujpe63.5.458

B.I. Verkin, and A.A. Galkin

I.P. ZHARKOV ${ }^{1}$ A.G. DEMISHEV ${ }^{2}$

${ }^{1}$ Institute of Physics, Nat. Acad. of Sci. of Ukraine

(46, Nauky Ave., Kyiv 03028, Ukraine)

2 A.A. Galkin Institute for Physics and Engineering of Donetsk, Nat. Acad. of Sci. of Ukraine

(72, R. Luxemburg Str., Donetsk 83114, Ukraine)

\title{
ON THE HISTORY OF CRYOGENIC INSTRUMENT MAKING IN UKRAINE
}

The history of cryogenic instrument making in Ukraine has been briefly described.

Ke ywords: cryostat, cryogenic instrument making, history.

\section{Introduction}

The year of 2018 has a special meaning for the scientific community in Ukraine. In particular, November 27, 2018 will mark the centenary of the foundation of the National Academy of Sciences of Ukraine (NASU). The same year, it will be the 90th anniversary of the foundation of the Ukrainian PhysicoTechnical Institute (UPTI), which became a parent of cryogenics in Ukraine and an alma mater for a number of famous institutes of the NASU, such as the National Science Center Kharkiv Institute of Physics and Technology (NSC KIPT), A.Ya. Usikov Institute of Radiophysics and Electronics (Kharkiv, IRE), B.I. Verkin Institute for Low Temperature Physics and Engineering (Kharkiv, ILTPE), Institute of Radio Astronomy (Kharkiv, IRA), and A.I. Kalmykov Radiophysical Sensing Center (Kharkiv, RSC). The "grandchildren" of UPTI are the A.A. Galkin Institute for Physics and Engineering (Donetsk, DonIPE) and the Institute for Problems of Cryobiology and Cryomedicine (Kharkiv, IPCC) created on the basis of the ILTPE. Furthermore, the next year will mark the 90th anniversary of the Institute of Physics of the NASU (Kyiv), one of the leading institutions in the cryogenic engineering.

Therefore, let us dwell on the main historical milestones marking the appearance of cryogenics in Ukraine in more details. It is hardly possible to cover the whole process of cryogenics evolution in Ukraine

(C) I.P. ZHARKOV, A.G. DEMISHEV, 2018 within the framework of one article. So, let us try to consider the main works of only the ILPTE, the DonIPE, and the Institute of Physics. This paper is devoted to the memory of their founders.

\section{The Beginning}

The year of 1928 preceded the first five-year plan for the development of all branches in the national economy of the Soviet Union. The role of science in this process was permanently growing. The organization of the Ukrainian Physico-Technical Institute (UPTI) in Kharkiv in 1928 opened a new page in the history of physics in Ukraine. In those years, Kharkiv was the capital of Ukraine, and the creation of an all-Ukrainian leading institute just in Kharkiv was quite understandable. Institute's task was to carry out physical researches and to help technically to the management of the large industrial center of Ukraine. The creation of UPTI was initiated by Academician A.F Ioffe, the director of the Leningrad Physico-Technical Institute.

The Ukrainian and Soviet governments actively supported the organization of the Institute. The following resolutions were adopted one after another: the resolution of the Supreme Council of National Economy of Ukraine dated May 16, 1928 and the resolution of the Supreme Council of National Economy of the USSR dated June 18, 1928. The same year, on October 30, the Council of People's Commissars of the Ukrainian SSR approved the Regulation on the UPTI. All issues concerning the financing of building, equipment, and territory were solved.

ISSN 2071-0194. Ukr. J. Phys. 2018. Vol. 63, No. 5 
The appointment of Ivan Vasilyevich Obreimov $[1,2]$ as the director of the Institute turned out a fortunate circumstance. At that time, I.V. Obreimov worked at the H. Kamerlingh Onnes laboratory, where he continued his researches started in Leningrad in 1925. The researches dealt with the verification of his ideas about the specific features in the behavior of the absorption spectra of molecular substances in the condensed state at low temperatures. Ivan Vasilyevich eagerly accepted his appointment. Here is his reply to the Organizing Committee of the Institute: "I am extremely affected that you did me the honor... I especially appreciate that the laboratory is destined for low temperatures. This is an area of my interests, and I hope that we will successfully agree".

It should be noted that, in 1928-1930, low temperature studies were rapidly developed, and there were three cryogenic laboratories throughout the world: the H. Kamerlingh Onnes laboratory in Leiden (liquid helium, since 1908), the McLennan laboratory in Toronto (helium liquefier according to the Kamerlingh Onnes technology, since 1923), and the V. Meissner laboratory in Berlin (the own design of helium liquefier, since 1925).

When working in Leiden, Ivan Vasilyevich did a great piece of job associated with placing the orders in Europe for a scientific equipment and nitrogen, hydrogen, and helium liquefying installations. As he told himself, he was occupied in Leiden not only with spectra; he worked for half a year in a company that manufactured a hydrogen liquefier, directly studying the entire machinery of cryogenic physics. He gratefully recalled the assistance of Prof. Kamerlingh Onnes and the chief Leiden mechanic Flim. Simultaneously, the Institute itself was being built very rapidly in Kharkiv. Its main building with the cryogenic laboratory was started to be built in 1928, and the equipment was begun to be mounted already in 1930. Simultaneously, an apartment house was being built for the staff; it was ready by the beginning of 1930 .

Extremely important was the fact that, already in 1929, the first UPTI employees at the Institute directed by the resident of Leningrad, I.V. Obreimov, were the residents of Kharkiv. These were Professors A.V. Zhelekhovskii, A.A. Slutskin, D.S. Shteinberg, M.Yu. Pomazanov, and M.I. Dorogoi. The well-known scientists P.L. Kapitsa, D.A. Rozhanskii,
G.A. Gamov, and P.S. Ehrenfest were invited as consultants of the Institute.

In May 1930, a powerful scientific "landing group" from Leningrad was missioned to Kharkiv. The group of 16 persons included professional physicists A.I. Leipunskii, A.F. Prikhotko, Yu.N. Ryabinin, N.A. Brilliantov, G.D. Latyshev, A.V. Stepanov, Ya.S. Kan, V.S. Gorskii, D.D. Ivanenko, P.I. Strelnikov; later, L.V. Shubnikov, O.N. Trapeznikova, K.D. Sinelnikov, and A.K. Valter. In 1933, L.D. Landau ultimately relocated to Kharkiv.

The glass blower E.V. Petushkov also relocated. He was a virtuoso specialist, who created a large glassblowing school. He manufactured glass cryostats for research works, the application of which allowed plenty of complicated experiments in various researches to be carried out successfully. "What would the UPTIers do without Petushkov?..."

Thus, a complex subject matter of the Institute was elaborated. It included condensed-matter physics, low-temperature physics, nuclear physics, electromagnetic oscillations, and theoretical physics.

\section{Production of First Cryogenic Liquids}

In 1930, the Institute obtained and put into operation a nitrogen liquefier of the Heyland company $(25 \mathrm{l} / \mathrm{h})$.

At first, Ivan Vasilyevich intended the cryogenic laboratory to study crystals, which would continue his Leiden researches in molecular spectroscopy. The first cryogenic work published in the first volume of a new journal Physikalische Zeitschrift der Sowjetunion was the paper by I.V Obreimov and A.F. Prikhotko "Die Absorptionsspectren der Kristalle einiger Verbindungen der aromatischen Reihe bei niedrigen Temperaturen. I". Later, when liquid hydrogen and liquid helium were obtained, there followed a series of researches and publications, which initiated a broad scientific direction: molecular spectroscopy and cryocrystals.

Another direction was developed in parallel. A number of relevant works were published: I.V. Obreimov, N.A. Brilliantov, V.I. Startsev. On the nature of plastic deformation. I-IV (Sow. Phys. and Zh. Ekksp. Teor. Fiz., 1933-1939); W.S. Gorsky. On the transition in the $\mathrm{Cu}-\mathrm{Au}$ alloys. I-IV (Sow. Phys. and Zh. Eksp. Teor. Fiz., 1934-1936); R.I. Garber. Latent energy and residual stresses of plastically 
deformed rock salt (Zh. Èksp. Teor. Fiz., 1936). This direction was developed broadly and very successfully; first at the UPTI, and afterwards at the ILTPE and other institutes.

In 1930, at the instance of A.F. Ioffe, Ivan Vasilyevich Obreimov invited a talented physicist Lev Vasilyevich Shubnikov to Kharkiv. At the UPTI, L.V. Shubnikov developed works dealing with the problems of superconductivity, magnetism, thermal properties of substances, liquid helium, and so forth. In 1931, I.V. Obreimov divided the cryogenic laboratory into two units: the laboratory of crystals and the cryogenic laboratory, in its true meaning, with the subject matter of Lev Vasilyevich that was mainly formed in Leiden. The laboratory began to obtain the equipment ordered by Ivan Vasilyevich.

First employees comprised the staff of the cryogenic laboratory: Yu.N. Ryabinin, V.I. Khotkevich, I.P. Korolev, A.I. Sudovtsov, and V.I. Bogatov. Their names became more and more known. Their work formed a basis for the further development of the cryogenic laboratory and its efficiency.

On March 23, 1931, a hydrogen liquefier, the first in the Soviet Union, was launched. First, it was a small liquefier with a production capacity of $1.5 \mathrm{l} / \mathrm{h}$; later, a large liquefier producing $6 \mathrm{l} / \mathrm{h}$. One cannot help recalling the irony revealed by Meissner who watched how Ivan Vasilyevich mastered the hydrogen liquefier in the Linde company. On this occasion, Ivan Vasilyevich told at the grand meeting devoted to the 40th anniversary of the UPTI: "I remember my meeting with Prof. Meissner at the Berliner Reichsanstalt (an analog of our Institute of Metrology) in 1928. He told me: 'Do you want to possess a liquid-hydrogen machine? The matter is whether you will have a mechanic who will be cultured enough to handle it. I myself could not get such a mechanic, and I myself handle this installation. The other people also work on it, and I serve them. Of course, German mechanics are more cultured than Russian mechanics. If I could not find a cultured enough mechanic in Germany, then you will not find such a person in Russia. So, your destiny is as follows: You will be a mechanic at the machine, and the others will work with liquid hydrogen. Nevertheless, I will readily help you ...' But Meissner's propensity did not come into being. There is a laboratory notebook where the dates of hydrogen installation launching are handwritten by L.V. Shub- nikov, Yu.N. Ryabinin, V.I. Khotkevich, I.P. Korolev, V.I. Bogatov, and A.I. Sudovtsov. The required mechanics were found!"

The work of I.V. Obreimov and A.F. Prikhotko on molecular spectroscopy, which the former started long ago in Leningrad and continued in Leiden till 1928, was developed. It is no exaggeration to say that the appearance and the initial development of such scientific domains as low-temperature spectroscopy and magneto-optics, which have now obtained both experimental and theoretical development, as well as international recognition, were mainly a result of the researches carried out at the UPTI.

A helium liquefier (about $1.5 \mathrm{l} / \mathrm{h}$ ) was obtained by the end of 1932. This liquefier was developed by Meissner, and it was identical to the author's variant available at the Berlin laboratory. But even Meissner himself, who arrived with his co-worker in accordance with the contract, could not launch it. It was stated that the installation defects could not be eliminated in Kharkiv, and, for this purpose, the installation had to be sent backward. Of course, it was an unpleasant delay of the whole work. Of course, the required mechanics "on helium" revealed themselves again, and the liquefier was repaired in-house and launched in 1933. (A.I. Sudovtsov told that when the mechanics opened the liquefier, they did not believe their eyes, when having seen how roughly the tubes of a heat exchanger had been soldered.)

Fortunately, L.V. Shubnikov did not wait when the ordered helium liquefier would arrive. A few liquefiers were fabricated in 1932 on the basis of the one-shot adiabatic mechanism developed by F. Simon. Lev Vasilyevich became closely acquainted with him in Leiden and received, before the publication, a detailed description of this device, which was technically quite simple. Making use of this liquefier, which was transformed into a measuring device, the first fundamental results were obtained by the end of 1932 , in particular, the discovery of the absolute diamagnetism of a superconductor at $T<T_{\mathrm{c}}$, which is now known as the Meissner effect.

In 1934, the Meissner liquefier began to work regularly with a productive capacity of about $1.4 \mathrm{l}$ of liquid helium per hour, a very significant value at that time. The launch of the Meissner liquefier with a rather good productivity made it possible to immediately expand the scope of researches and implement intentions.

ISSN 2071-0194. Ukr. J. Phys. 2018. Vol. 63, No. 5 
It should be noted that the first cryogenic workshop for students in the Soviet Union was organized by L.V. Shubnikov in 1935. At that time, it was held at the UPTI, in the premises of the cryogenic laboratory. Students from Leningrad and Sverdlovsk also did practical work there.

In 1935, a cryogenic laboratory for deep cooling was created at the UPTI. The laboratory was headed by M. Rueman. It became a basis for an experimental station of deep cooling. Till 1938, it had been a branch of the Institute, an organization that should optimize a number of coke-chemical processes in metallurgy and autogenous industry. It was the first daughter organization of the UPTI cryogenic laboratory, to which some of its employees were transferred: M.F. Fedorova, N.S. Rudenko, E.S. Borovik, and N.M. Tsin, as well as A.R. Yastrebenetskii from the Institute of Chemical Technology.

\section{First Metal Dewar Vessels and First Liquid Helium of Domestic Production}

In 1935-1936, the technology and equipment to manufacture metal Dewar vessels up to 50 liters were developed, and their serial production was organized. All relevant documentation was transferred to the Moscow Autogenous Plant, which organized their industrial manufacture (V.I. Kostenets, A.I. Drei).

In 1936-1938, the laboratory exemplar of a Kapitsa liquefier was made in the workshop and was being tested. First liters of helium of own production were obtained (A.I. Parusov, A.I. Sudovtsov, I.P. Korolev, and V.I. Khotkevich).

It should be emphasized that the launch and mastering of machines for the production of liquid hydrogen and liquid helium were outstanding events at that time. In the first years of the UPTI cryogenic laboratory, a number of cornerstone results were obtained by studying superconductivity, magnetism, thermal properties, and the properties of liquid helium. New concepts were generated.

In 1936, I.V. Kurchatov and G.Ya. Shchepkin from the LPTI, together with L.V. Shubnikov and A.I. Leipunskii, carried out a research of the neutron slowing down and absorption at liquid-hydrogen temperatures. Besides the essence of the matter, the following circumstance was of interest: liquid hydrogen in a quantity of 50 liters was used in one device, perhaps for the first time in the world practice.
By the beginning of 1937, the development of planned directions and the results obtained in the low temperature physics turned out so significant that, on January 23-25, 1937, the Academy of Sciences of the USSR (AS USSR) organized the first visiting session of the physical group (Branch) at the UPTI in Kharkiv. Actually, it was the first of allUnion meetings on low temperature physics. Later, they have been regularly organized till recently. The meeting was chaired by Academician A.F. Ioffe. The meeting was participated by Academician S.I. Vavilov, the Corresponding member G.S. Landsberg, the Corresponding member V.A. Fock, Academician of the Academy of Sciences of the Ukrainian SSR (AS UkrSSR) A.G. Gol'dman, Prof. Ya.I. Frenkel, as well as researchers from Moscow, Leningrad, Sverdlovsk, Kyiv, Odessa, and Dnepropetrovsk; together about 200 persons.

\section{Prewar and War Years}

Such wonderful prospects! But suddenly... In 19371941, the UPTI together with its cryogenic laboratory (and the whole country) experienced tragic events. Under the lawlessness of that time, some of the UPTI employees were repressed: the director of the UPTI, Academician of the AS UkrSSR, Aleksandr Ilyich Leipunskii (1938); the founder of the Institute, the Corresponding Member of the AS USSR Ivan Vasilyevich Obreimov (1938-1941), and the head of the cryogenic laboratory Lev Vasilyevich Shubnikov (1937). Alexander Ilyich and Ivan Vasilyevich returned from the "other world"; Lev Vasilyevich remained there...

Nevertheless, the UPTI cryogenic laboratory continued its functioning. There appeared new research directions and new names. Later, some of them became widely known: A.A. Galkin, B.N. Eselson, N.M. Nakhimovich (all the three started to work at the laboratory in 1938, before the graduation from the University), and L.S. Kan (from 1938). In 1940, B.I. Verkin became a post-graduate student.

After the beginning of the Great Patriotic War, the Institute was evacuated to Alma-Ata, the capital of Kazakhstan (more than $4.500 \mathrm{~km}$ from Kharkiv), for 903 days together with the scientific and engineering equipment and employees. At the new place and under special conditions, practically every required task was solved and immediately implemented: 
- An effective chemical igniter was developed for bottles with an inflammable mixture (N.S. Rudenko in consultation with E.S. Khotinskii, Professor of the Kharkiv State University). As is known, the variants of this ammunition were widely and successfully used against tanks. All procedures for manufacturing BIUPTI (bottle igniter UPTI) were elaborated. A team of workers was formed (B.G. Lazarev, N.S. Rudenko, V.I. Khotkevich, L.S. Kan, Ya.S. Kan, B.I. Verkin, and others). The mass production of this ammunition, which was tested and adopted by the engineering department of the Kharkiv military district (KhMD), was quickly organized.

- At the Balkhash copper smeltery, one of the two copper smelteries providing war needs and put into operation just before the war, the production losses of copper were reduced by a factor of three with the help of UPTI specialists. In 1944, B.G. Lazarev, I.E. Nakhutin, and V.S. Shpinel were awarded the Diploma of the Supreme Council of Kazakhstan "For the elaboration of scientific and engineering problems having the national-economy and defense value".

- Within the months of the German troops defeat at Stalingrad, on demand of the People's Commissariat of Defense and on the basis of the prewar works by V.I. Khotkevich, there were developed two types of a new high-calorific thermite of military application. They were adopted for use, and their fabrication was implemented in Moscow (V.I. Khotkevich, B.G. Lazarev). A workshop was organized to restore electric light bulbs, in particular, for the Balkhash plant. The workshop had been functioning during the whole war period (E.V. Petushkov).

At the "free time", March-December 1943, a cryogenic seminar, mainly theoretical, was held with detailed reports on the papers prepared for publication (all laboratory notebooks were evacuated). From December 30, 1942 to January 3, 1943, a session of the AS USSR was held in Ufa, where the Presidium of the Academy of Sciences, the Institute of Physics and Mathematics, and some of the UIPT employees were located at that time. The Alma-Ata group (I.M. Lifshits, A.I. Akhiezer, B.G. Lazarev) and the UIPTers living in Ufa (A.F. Prikhotko, G.D. Latyshev) participated in the session with reports. The Academy created plans for 1943.

In May 1943, a four-day scientific session of the Institute was held in Alma-Ata. Twenty-nine reports were made concerning all directions of Institute's ac- tivity, both theoretical (A.I. Akhiezer, I.M. Lifshits) and experimental (K.D. Sinelnikov, A.K. Valter, A.A. Slutskin, B.G. Lazarev, V.I. Khotkevich, Ya.S. Kan, L.S. Kan, and some others). The same year, B.G. Lazarev defended his doctoral thesis "Some researches in superconductivity" at the Joint Council of the Institutes of Physics and Mathematics of the AS UkrSSR in Ufa. Eight works of the Institute scientists were published in the Zhurnal Eksperimentalnoi $i$ Teoreticheskoi Fiziki and Journal of Physics in 1942-1944.

\section{Postwar Years}

After the war, the Physico-Technical Institute returned to Kharkiv. This was a salvation of the Institute achieved due to the efforts of K.D. Sinelnikov, A.I. Leipunskii, I.V. Obreimov, A.A. Slutskin, A.K. Valter, and G.V. Kurdyumov, who were already in Moscow by that time. There was a government decree dated April 8, 1944 on the re-evacuation of the UPTI. The Institute returned to Kharkiv.

What about the Institute buildings? The German troops, when being expelled from Kharkiv, among other objects, had blew up, as they did everywhere, the central three-storey part of the Institute. According to the estimation of a standard professional German sapper, the explosive placed at the bearing base under the vestibule had to destroy the building. However, the outer frame of the main building remained intact, although the door was thrown 50 meters away by the explosion, the window glasses were broken... Instead of the vestibule, there was a hole. The floors and, partly, the ceiling in the corridors that radially diverged from the vestibule, including the corridor to the cryogenic laboratory, were destroyed over a considerable length. But in whole, the building survived.

"They did not know that the UPTI stands on the "bones" of the "Empress Maria", Ivan Vasilyevich Obreimov told. Really, the dreadnought "Empress Maria" was torpedoed near the Odessa coast by the cruisers Geben and Bressau, which the Turks allowed to enter the Black Sea through the Dardanelles in the First World War. Ivan Vasilyevich somehow managed to obtain a permission for steel I-beams from the hull of this ship. They were used as central pillars of the building and withstood the explosion. Even now, the wounds obtained at that explo-

ISSN 2071-0194. Ukr. J. Phys. 2018. Vol. 63, No. 5 
sion can be seen on the "bones" in the Institute basement.

Well, what about the cryogenic laboratory? I.V. Obreimov told: "... Our cryogenic lab was constructed as follows. All four rooms (the main halls) were covered with a light roof, which could be elevated by rails. In the case of explosion, the explosion force should raise the roof, which afterward should return back to its place. Such a thing cannot be tested. But the test was performed by the fascists... The blast wave ran along the cryogenic lab corridor, the roof lifted and returned back to its place. The huge windows, which were designed as safety valves for such a case, were shuttered. According to Ivan Vasilyevich, the roof, indeed, snapped into action: only small cracks remained near the ceiling. In all halls, the installation seatings were intact. Till the last moment before the leaving, the Germans did not know about copper pipelines that ran through all rooms to hydrogen and helium gas holders (they were painted). The Nazis only sawed them and demounted from the walls, but left them in a hurry. A significant role in their preservation, as well as in the preservation of oil in gasholders, was played by Ivan Pavlovich Korolev, the chief mechanic of the cryogenic workshop, who remained in Kharkiv with his family. In particular, he filled all hydrogen and helium pipelines with oil engulfed from gasholders.

The cryogenic seminar was renewed. The seminar diary documents it since the fall of 1944 . Three reports were made by I.M. Lifshitz about his work on stresses of the second kind. A few seminars were devoted to the discussion of the plans for 1945. December 1944 and January 1945 were occupied by the lectures on the solid state theory (A.S. Kompaneets), Bridgman's work with high pressures (V.L. German), and reports about publications: on the second sound in helium (P.V. Peshkov), the magnet levitation above a superconductor (V.K. Arkadyev), the thermomolecular pressure difference, and others. The seminars stopped on May 26, 1945, when the recovery work in the cryogenic laboratory was continued.

\section{Restoration of Cryogenic Basis}

By November 1, 1946, the nitrogen, hydrogen, and helium installations were launched one by one! The hydrogen and helium pipelines from liquefiers and gasholders to the measuring devices in the halls of the main building were restored. Simultaneously, the task of demobilization of the cryogenic laboratory employees from the army and from various evacuation sites was being successfully solved. The correspondence with all of them was established and maintained during the war. All of them dreamed to return to the UPTI; they aspired to their scientific home. The correspondence with the military authorities quickly resulted in the demobilization of A.A. Galkin (artilleryman), N.S. Rudenko (rank), and B.N. Eselson (artilleryman). N.S. Rudenko, after recovering from concussion, was delayed at a military hospital as an expert in the maintenance of Xray installations. He was a truly excellent physicist, a broad-range experimenter. B.N. Eselson, after concussion and hospital, taught at a military school. The most difficult situation was with B.I. Verkin. After the war, he turned out to be the deputy commander for political affairs at the Suvorov Military School in Novocherkassk. Servicemen of this category were the most difficult to be discharged from the military service. It was Kurchatov's program that helped in this situation.

E.S. Borovik and N.M. Tsin also returned. Since 1938, they had been working at the UPTI daughter enterprise, the Experimental deep-cooling station. The latter was evacuated to Kemerovo (the south-east of Western Siberia), entered there into the nitrogen fertilizer plant, and, unfortunately, did not return as a whole entity to Kharkiv. A very valuable link in the chain "cryogenic science-cryogenic technology" has been lost. A.I. Sudovtsov returned from the Irkutsk aircraft factory. After graduating from the Kharkiv Aviation Institute in 1941, he worked there in the wartime as a control master and, later, as an engineer. V.I. Khotkevich came from Alma-Ata somewhat later. The head of the mechanic workshop N.S. Dogadin was demobilized from the army. New remarkable mechanics appeared at the Institute: M.N. Masalitin and A. Karushi came from navy, and V.V. Zolotarev from aviation.

A very rapid restoration of the Institute and, simultaneously, the cryogenic laboratory was connected with the fact that the UPTI was maximally engaged into a large Kurchatov's program on the uranium problem. The corresponding works have already been started since the beginning of 1947.

The years of 1947-1951. The initial data for the designing of a large-capacity installation for extracting heavy hydrogen from natural liquid hydrogen by 
its rectification were determined, calculated, and presented: an industrially feasible technology for producing superpure hydrogen, the impact strength and plasticity of alloys chosen for the installation components at a temperature of $20.4 \mathrm{~K}$, and the design of the non-vacuum thermal insulation of the installation. A laboratory model of the installation for the cryogenic non-mechanical pumping of the uranium hexafluoride gas was elaborated. A simple efficient technique and the corresponding device for the batch hermetic control of the variants of aluminum shells for uranium blocks in water at temperatures up to the critical one have been developed and applied.

\section{First Domestic Liqueurs}

The number of works, in which liquid helium was used, grew permanently, especially in the postwar period. The productivity of the Meissner liquefier was already not enough. It should be said that a large experience in the cryogenic technology had been accumulated by that time. Furthermore, there was an important psychological factor formed during the war: to fulfil what seems to be impossible. In the late 1940s, A.I. Sudovtsov together with the mechanics from the cryogenic laboratory creates liquefiers of their own design: for helium with a capacity of up to $20 \mathrm{l} / \mathrm{h}$, and for hydrogen with a higher productivity of course. The parameters of those liquefiers were at the level of the best Leiden liquefiers at that time.

The 1950s (1947-1963) were really remarkable creative and successful years. At the reconstructed cryogenic laboratory (1947), the research directions that had been formulated by 1941 in the metal physics, helium physics, and other domains were widely implemented. The results quickly grew together with their talented "bearers" and led to the creation of new directions and concepts in the condensed matter physics. There was a "flood" of dissertations defended at the cryogenic laboratory in 1943-1959, which included 5 Dr.Sci. and 11 Ph.D. theses. In particular, A.F. Prikhotko defended her doctoral thesis in 1943 and became the first woman in the Soviet Union with the title of Dr.Sci. in physics and mathematics. A.A. Galkin and E.S. Borovik defended their theses in 1954, and B.I. Verkin in 1958. It becomes cramped for the growing nestlings in parents' nest, and they strive for freedom. A.F. Prikhotko was the first who moved to Kyiv after Ukraine had been liberated from the Nazi occupation in 1944. In Kyiv, she organized a spectral laboratory at the Institute of Physics of the AS UkrSSR. Later, the laboratory became the world's largest center for low-temperature spectroscopy of non-metal crystals. On the initiative of A.F. Prikhotko, with the help of the UPTI specialist A.I. Sudovtsov and on the basis of a liquefier of his own design, a cryogenic laboratory, the second in Ukraine and the third in the Soviet Union, was created at the Institute of Physics of the AS UkrSSR in 1954. After the reconstruction and expansion, this laboratory served for a long time as a base of lowtemperature reseaches for a number of scientific institutions in Kyiv.

\section{Extension of Cryogenic Basis in the USSR}

The laboratories of this kind began to be created in Leningrad, Sverdlovsk, Sukhumi, and Baku from the beginning of the 1950s, and the UPTI - namely, its cryogenic laboratory! - helped in this matter. In 1953, the first cryogenic laboratory from this series began to work at the LPTI. It was organized by N.M. Reinov. Kyiv (the Institute of Physics of the AS UkrSSR) followed in 1954. A.F. Prikhotko and A.I. Sudovtsov telegraphed about the launch of liquefiers. A telegram from Sverdlovsk (the Institute of Metal Physics of the Ural Branch of the AS USSR) informed in 1957: "We are glad to inform about the production of liquid helium on the Urals. We thank for your permanent attention and help. Mikheev, Vonsovskii, Volkenshtein". It is interesting to note that N.V. Volkenshtein arrived to take away the liquefier in a trophy (after Stalingrad) car of F. Paulus's staff. The car was handed over by the Military Commander to the Ural branch of the Academy of Sciences. In 1959, a letter from the director of the Sukhumi Physico-Technical Institute was received: "... three days ago, the first liter of helium was obtained". The A.I. Sudovtsov liqueurs worked at those new cryogenic laboratories.

By the beginning of the 1950s, there were three large centers of low-temperature physics in the USSR. In essence, they covered all main problems in this domain of science. In the chronological order, these are the UPTI in Kharkiv, the Institute of Physical Problems in Moscow, and the Institute of Physics of the Academy of Sciences of the Georgian SSR in Tbilisi. As was mentioned above, the cryogenic laboratories at the Leningrad Physico-Technical Institute, the Institute of Physics of the AS UkrSSR (Kyiv), and the 
Institute of Metal Physics of the Ural Branch of the AS USSR (Sverdlovsk) were created, to a large extent, with the assistance of the cryogenic laboratory of the Ukrainian Physico-Technical Institute.

In 1958, E.S. Borovik organized the second cryogenic laboratory as a part of the Department of Plasma Physics (at the KIPT). Its first works were associated with the problem of that period, the creation and confinement of plasma. In 1961, liquefiers of helium and hydrogen were launched. The laboratory dealt with strong magnetic fields: first, pulsed fields up to $100 \mathrm{kOe}$ created, by using coils cooled by liquid hydrogen; then, large helium-cooled magnetic devices based on superconductors, high cryogenic vacuum, and supersonic gas jets in vacuum.

In 1963, the UPTI supplied liquid helium to the Center for Long-Range Space Communications in Crimea. For the first time, a low-noise paramagnetic amplifier, maser, on a ruby crystal cooled with liquid helium was applied at the receiver input.

In 1967, the cryogenic laboratory at the Kharkiv University, which was organized by the "old cryogenic master" V.I. Khotkevich (from 1967, the Corresponding Member of the AS UkrSSR), began to produce and consume its own helium. The creation of this laboratory was natural taking into account the availability of the post-graduate specialization in lowtemperature physics and a large scientific-research laboratory.

The Moscow branch of the UPTI school headed by L.F. Vereshchagin, also from the generation of the 1950s, is also of interest. Being highly enthusiastic in high-pressure researches, L.F. Vereshchagin got training at the laboratories of I.V. Obreimov and L.V. Shubnikov (in 1930-1939) and headed the laboratory of high-pressure physics at the Institute of Organic Chemistry of the AS USSR. In 1958, he organized the Institute of High-Pressure Physics of the AS USSR, which now bears his name.

Attention should be attracted to the creation of a new direction of researches at the UPTI, new ideas: high-pressure physics at arbitrarily low temperatures.

But let us return back to the "nestlings".

\section{Development of Applied \\ Researches and Cryogenic Instrument Making in Ukraine}

In accordance with the resolution of the Council of Ministers of the Ukrainian SSR No. 681 dated May
11, 1960, the Presidium of the AS UkrSSR issued a decree dated May 13, 1960 about the organization of the Institute for Low-Temperature Physics and Engineering (ILTPE) of the AS UkrSSR in Kharkiv and its subordination to the Branch of Physics and Mathematics of the AS UkrSSR. This decree was preceded by an intensive preparatory work of the initiative group headed by B.I. Verkin, who was the UPTI employee at that time. This group included A.A. Galkin, I.M. Dmitrenko, B.I. Eselson, and V.I. Startsev [3]. The great support was obtained from P.L. Kapitsa, who headed the Council on the Problem of LowTemperature Physics at the AS USSR. At its meeting in July 1959, the Council approved the scientific themes of the future institute and adopted a decision to provide assistance in its organization.

Since the day of ILTPE foundation, applied physical and technical researches were carried out along with fundamental ones. In 1970, the scientific and application department, where those studies were performed, was transformed into an independent rapidly developing self-supporting unit of the Institute, known from the 1980 s as the Special Design and Technological Bureau (SDTB) for cryogenic technology. Actually, the SDTB was a large specialized interdisciplinary scientific-research institution with experimental production workshops (in Kharkiv and Valki). The main directions of the SDTB activity were formulated by B.I. Verkin, and all the work was performed under his direct scientific supervision. B.I. Verkin almost unmistakably chose those cryogenic applications that were maximally efficient for the development of a number of branches in new technology, national economy, and medicine [4].

The creative union of physicists, mathematicians, engineers, and designers, their orientation at the solution of the most urgent problems in physics and mathematics, and the implementation of the obtained solutions in the prototypes of the newest cryogenic equipment, all that, together, gave a powerful impetus for the development of the young Institute, with the average age of its employees being 26 years in the early $1960 \mathrm{~s}$.

On the initiative of B.I. Verkin and with his direct participation, new, in the USSR, scientific and engineering directions arose at the ILTPT in 1960, such as the on-ground simulation of outer space conditions, the space and cryogenic materials science, 
and the development of various on-board systems and instruments.

In the works by Boris Ieremievich and his colleagues (I.O. Kulik, N.N. Bagrov, A.A. Guslyakov, A.M. Kislov, and others), the physical fundamentals of the outer space simulation were formulated and the calculation principles for nonequilibrium cryovacuum systems were proposed. On the basis of those studies, various ultrahigh-vacuum (with a pressure of down to $10^{-13}$ Torr) chambers with a useful volume from 0.2 to $14000 \mathrm{~m}^{3}$ were developed, which imitated the cosmic environment, first of all, the cosmic vacuum. The elaborations of the Institute gave start to the industrial production of large high-vacuum chambers and their cryogenic panels in the USSR.

Later, the created vacuum-simulating chambers included the sources of cosmic radiation (vacuum ultraviolet, and electron and proton fluxes with energies from 20 to $200 \mathrm{keV}$ ) developed at the ILTPE (E.T. Verkhovtseva and A.M. Markus), a mass spectrometer to study the distribution of molecular fluxes and the kinetics of physicochemical processes, a system of orbital thermal changes, and so forth. Smallsized gas-jet sources for the simulation of vacuum ultra-violet and ultrasoft X-radiation of several types, which were developed in 1974-1980, were awarded the gold, silver, and bronze medals of the Exhibition of Economic Achievements (VDNKh), and continue to be applied nowadays both in Ukraine and abroad (Germany, China). The first, in the USSR, a radiofrequency monopolar mass spectrometer ROMS-1 (N.N. Bagrov, A.G. Furmanskii, and others) was created at the ILTPE in 1968. Later, a batch of portable high-sensitive mass spectrometers of the ROMS type was elaborated, which were awarded 18 medals and diplomas at domestic (VDNKh) and international exhibitions. About 1500 ground-based mass spectrometers were fabricated, which worked in more than 80 organizations in various countries (USSR, Bulgaria, Poland).

On the basis of all those developments, under the guidance of B.I. Verkin with his colleagues A.E. Yanov and V.I. Bondarenko, and, later, under the guidance of V.V. Eremenko, who became the director of the ILTPE in 1991, with V.V. Abraimov, L.K. Kolybaev, Yu.A. Pokhil, Yu.A. Melenevski, and A.M. Kislov, several generations of complex space simulators were created during the period from 1960 to 2001 to solve the problems of space materials sci- ence and test separate units, aggregates, and satellites in whole. Simulators of the last generation (the simulation of 8 space factors) obtained the international recognition and now successfully work at the scientific and research institutes in other countries (Berlin, Germany; Harbin and Lien Jou, China). A stand for thermo-vacuum satellite testing at the production association "Yuzhmashzavod", which was created at the ILTPE, is used for the thermal testing of domestic and foreign satellites.

On the initiative of B.I. Verkin and under the direction of V.Y. Ilyichev, M.V. Zinoviev, V.V. Boichuk, V.K. Chernetskii, V.F. Udovenko, G.D. Gamulya, and others, original cryogenic vacuum installations were created to study mechanical, static, dynamic, and frictional properties. The installations are also used at other institutes both in Ukraine and abroad.

The simulation and testing equipment created at the ILTPE was used to perform complex studies of the influence of cosmic vacuum, radiation, low temperatures, and thermal force loads on the strength, fatigue, and frictional properties of constructional materials. The results of those researches were included into manuals and normative documents. They were used while building the launching complex in Baikonur, creating on-board mechanisms and devices for the spacecrafts of the USSR and Ukraine, developing cryogenic-vacuum and superconducting equipment. These works were awarded the State Prize of the Ukrainian SSR, the Paton Prize of the AS UkrSSR, medals of the VDNKh of the USSR.

In the 1960s, in the framework of the development of various on-board systems and devices, B.I. Verkin initiated the following programs:

- cryostat systems for on-board space equipment; passive and, later, active cryostating systems;

- low-temperature thermometry;

- on-board mass spectrometers.

All those developments would be impossible without the fundamental and applied researches in the field of hydromechanics under zero-gravity conditions, as well as researches in the physics of cryogenic liquid boiling and heat transfer at boiling, under microgravity conditions, in the field of centrifugal forces, and in confined volumes, and the study of hydrodynamics and heat transfer at the motion in the channels. The corresponding work was begun in the mid-1960s at the Department of Applied Mathematics headed by A.D. Myshkis and the experimen-

ISSN 2071-0194. Ukr. J. Phys. 2018. Vol. 63, No. 5 
tal department headed by Yu.A. Kirichenko. The first world's monograph on zero-gravity hydromechanics was published at the ILTPE. Important and pioneer results were obtained on the heat and mass transfer, which are necessary to understand the behavior of cryogenic liquids as components of a rocket fuel and cooling elements of on-board cryostat systems.

On the basis of the results obtained while studying heat and mass transfer in porous cryocrystals and screen-vacuum isolation, B.I. Verkin, R.S. Mikhalchenko, V.T. Arkhipov, V.F. Getmanets, and others created the first domestic on-board sublimation systems for the thermostating in a temperature interval of $10-200 \mathrm{~K}$ with an operation time of up to a year. The first of long-term cryostats (for 5 months) on solid nitrogen, KT-7, was used aboard the Salyut4 station in order to cool the IR receiver of the ITS-K telescope. In 1989, with the participation of V.D. Vakulenko, V.S. Rubtsov, and A.V. Borisenko, a pilot on-board specimen of a combined deep cooling system was created, which allowed the optoelectronic equipment with a heat release from 2 to $6 \mathrm{~W}$ at temperatures from 84 to $90 \mathrm{~K}$ to be cryostated for up to 5 years.

Together with researchers from other institutions, the scientists from the ILTPE used mass spectrometers to analyze the composition of the upper atmosphere layers and to make the geophysical prospecting of minerals. Devices of the ROMS type were installed on the landing stages of the Venus-9 and Venus-10 stations and, with their help, an isotopic and chemical analysis of the Venusian atmosphere was carried out along the parachute descent path. Mass spectrometers of the second generation - R-10, AMS10 , and RMS-10 - were developed for operating in open space at satellites and orbital stations (A.P. Pilipenko, L.L. Solodovnik, and A.D. Yarmak).

In 1961, on the initiative of I.M. Dmitrenko and under the direction of S.P. Logvinenko, works were organized aimed at the development of solid-state cryogenic thermometers. A family of $p$-GaAs-based thermocouples of the TSAD type was developed, and their fabrication was started. A metrological certificate for their serial production was obtained, and several thousands of cryogenic thermometers were fabricated, which were used both in the on-ground and on-board devices.

In 1970, B.I. Verkin, when creating a design department, initiated and headed a new direction of works in the cryogenic electrical engineering, the development of experimental specimens of cryogenic turbogenerators (CTGs) and acyclic machines (AMs). A.V. Pogorelov proposed a design for a synchronous generator with a superconducting excitation winding (SCEW), the first in the country. To fulfil those works, a number of design, calculation, material, and test departments were created in the framework of the design department, and a powerful experimental production workshop was developed.

In 1970-1985, B.I. Verkin and A.V. Pogorelov together with A.Ya. Yanov, F.M. Babenko, I.S. Zhitomirskii, V.F. Papakin, and others created a number of experimental cryoturbogenerators with a power from 0.2 to $10 \mathrm{MW}$, including country's first model exemplar of the KTG-2-2 cryoturbogenerator with rather a high power of $2 \mathrm{MW}$. The latter was used to verify the general design concepts and the basic design solutions for the units of future cryoelectromachines. A specialized electrotechnical organization, LPEO Electrosila, was engaged to create the KTG-2-2 generator and further generators (with a power of 5 and $10 \mathrm{MW}$ ). The experience accumulated in 1978-1984 while designing and testing model cryoturbogenerator specimens enabled the LPEO Electrosila together with the ILTPE to develop an experimental-industrial cryoturbogenerator with a power of $300 \mathrm{MW}$.

In 1970-1975, the scientific forces of the ILTPE (M.V. Zinovyev, L.K. Kolybaev, I.S. Zhitomirskii, and others) under the supervision of B.I. Verkin were combined with the potential of a large industrial enterprise, the Kharkiv Electromechanical Plant, in order to develop the first, in the USSR, acyclic machines with a SCEW. This combination led to the creation of AMs of two types: with the disk $(100 \mathrm{~kW})$ and cylindrical $(150 \mathrm{~kW})$ anchors, and with the collecting and annular current collectors, respectively. In 1976-1990, on demand of the Ministry of Shipping Industry of the USSR, the ILTPE developed a number of machines with extremely large mass and dimension parameters and a power up to $850 \mathrm{~kW}$. The machines had an optimized design of the cylindrical type, with an annular high-current collector with metal brushes, with a special lubrication and intensive cooling, and with an internal superconducting inductor mounted immovably inside the rotating anchors. For testing AMs with a SCEW, a unique stand, unique in the whole country, was created, which included a source of dc current 
of $12500 \mathrm{~A}$, load rheostats (1 MW), a control station, and a loading $750-\mathrm{kW}$ generator-engine with a balancing stator.

On the basis of the pioneering works in the domain of fundamental superconductivity carried out by B.I. Verkin, V.M. Dmitriev, V.I. Shnyrkov, S.I. Bondarenko, F.F. Mende, V.A. Pavlyuk, and others scientists of the ILTPE, the development of new physical and technical directions associated with the creation and application of cryoelectronic devices and devices with high levels of selectivity, sensitivity, and accuracy, was started; in particular, cryogenic electronics and radiophysics:

- superconducting quantum magnetometers and gradiometers for geophysical and medical applications;

- superconducting resonators and communication systems on their basis;

- superconducting receivers of electromagnetic and thermal radiation.

The story began from the creation of superconducting resonators in the 3 -cm range and, on their basis, the first accelerator system in the country that accelerated the electron beam to $250 \mathrm{kV}$. At that time, B.I. Verkin paid also considerable attention to the creation of other superconducting functional elements of cryoelectronics: superconducting bolometers, quantum interferometers, suspensions, magnetic screens, and so forth. The obtained results and the experience of technological and design solutions allowed B.I. Verkin, since the beginning of the 1970s, to significantly extend and intensify the activity in applied superconductivity. He organized a number of specialized self-supporting departments. As a result, there soon appeared cryoelectronic radio devices with unique parameters.

In 1975, B.I. Verkin, V.A. Konovodchenko, and others developed and fabricated the first helium-cooled infrared radiometer, in which a superconducting bolometer was used as a sensitive element. This radiometer was the first, in which a reflecting objective cooled with liquid helium was applied. Later, large-scale works were started to develop the infrared equipment for studying the structure of Earth's crust. A six-channel profile aviation radiometer was developed, and one specimen was given to the Institute of Physics in Prague. Then, a five-channel scanning radiometer was developed. Besides special works, it was used to study the structure of Earth's crust.
In 1976, B.I. Verkin, S.I. Bondarenko, and others developed country's first three-component superconducting quantum magnetometer with a sensitivity of $10^{-12} \mathrm{~T}$ for geophysical field researches and, in 1984, the world's first aviation superconducting quantum gradiometer with a sensitivity of $10^{-13} \mathrm{~T} / \mathrm{m}$ for geophysical works. Within the same period, superconducting magnetic screens were developed that provided the world's record-breaking magnetic vacuum at a level of $10^{-13} \mathrm{~T}$ in a volume of $1000 \mathrm{~cm}^{3}$. This made it possible to perform the metrological verification of ultra-sensitive magnetometers under almost any industrial noise conditions. For the first time, the influence of magnetic vacuum on the development of bacteria was revealed.

The capabilities of superconducting quantum magnetometers and bolometers were demonstrated for the first time in the course of unique multimonth geophysical and geological researches in Yakutiya (1976, 1977), Kazakhstan, and Ukraine (1978-1980). In addition, they were used in many scientific and research organizations throughout the country. On the initiative of B.I. Verkin, the ILTPE widely expanded scientific researches in a new direction, cryogenic optics. Stands and research facilities for testing optical materials and cryogenic optics at low temperatures were created. Materials, engineering solutions, and technological methods aimed at the solution of new problems were intensively searched. A full-scale model of the cosmic IR (360-mm) telescope for measuring the spectral characteristics of radiation from discrete and extended sources in the range of 6 $25 \mathrm{~mm}$ was developed and fabricated.

B.I. Verkin was one of the initiators of the development of effective and safe cryogenic technologies that use the stock of cold in liquid nitrogen, and the inert properties of liquid and gaseous nitrogen, as well as their introduction into the national economy. Under the direction of Boris Irememievich, nitrogen technologies were created to satisfy the needs of the agroindustrial complex, the building industry, pharmacology, and medicine. Those technologies allowed the delivery, storage, and processing of food products to be organized at a qualitatively new level.

In 1981-1986, at the ILTPE experimental production workshop in Valki, about 2500 refrigerators, each with a carrying capacity of $3-5$ tons for intraurban and regional transportation of perishable foodstuffs, were equipped with the nitrogen cooling sys- 
tem NAST-3 (V.I. Bondarenko, V.M. Boichuk, and others). In 1987, the serial production of refrigerated semitrailers KrioOdAZ with a payload capacity of 11 and 22 tons intended for the long-distance transport of perishable foodstuffs was started (on demand of Gosagroprom). Technologies were created for the fabrication of instant soluble natural beverages from fruit and berry powders based on the freeze-drying and cryomilling methods. Those technologies allowed the vitamin composition and the biologically active substances in the products, as well as their nutritional and taste qualities, to be maximally preserved. A work was performed aimed at the creation of installations for the rapid freezing and storing of fruits, vegetables, grain, and mixed fodders in a regulated nitrogen-based gaseous environment. Equipment and technical regulations for the cryomilling of various organic and inorganic materials, medicines, cement, minerals, metals, rubber, and plastics were developed.

The cryogenic medicine deserves special attention. It has been developed at the ILTPE since 1962 in two directions: low-temperature conservation and cryosurgery. B.I. Verkin together with V.G. Manzhelii, N.S. Pushkar, and other scientists carried out researches that resulted in the development of methods for the long-term conservation of nucleated blood cells, tissues, and bone marrow at low temperatures. At the ILTPE, a biocomplex was developed that provided a programmable freezing, storage, and warming of biological objects. For the needs of cryosurgery, which provides bloodless and painless operations, as well as shorter treatment periods, the SDTB employees (B.N. Murinets-Markevich, A.R. Krasnikov, M.E. Nosov, and V.Ya. Osipov) under the supervision of B.I. Verkin developed cryosurgical instruments and devices for the clinical application in dentistry, gynecology, obstetrics, dermatology, otolaryngology, ophthalmology, neurosurgery, and other fields of medicine.

As early as at the turn of the $1960 \mathrm{~s}-1970 \mathrm{~s}$, the ILTPE received a wide recognition of the scientific community both in the Soviet Union and far abroad owing to the excellent results obtained in experimental and theoretical studies of superconductivity, normal metals, magnetism, cryocrystal physics, liquid and solid helium, biophysics, low-temperature materials science, as well as in the domain of fundamental and applied mathematics. The research and develop- ment programs in space materials science were intensively realized, and applied elaborations in cryogenic instrument engineering were widely used. Various facilities to produce low and ultra-low temperatures were developed and launched.

In the 1980s, the Institute permanently increased the intensity of researches, by including high-temperature superconductivity, carbon materials, mesoscopic systems, and topical problems of mathematics into the scope of scientific interests. Substantial progress was attained in the development of superconducting electronic devices with the record sensitivity and stability levels. Experiments concerning the physical properties of helium were extended down to temperatures of a few millikelvins. Important results were obtained, while studying the electron properties of metals and researching their magnetic and galvanic properties. Researches in new directions were begun (the physics of molecular crystals, cryovacuum adsorption, and cryoelectronics). A large amount of work was done to create and implement new materials in electronic technique, cryogenic and space materials science, to use the results of researches of the properties of cryogenic liquids in the rocket technology. Effective methods were developed for the cryoconservation of blood cells, tissues, bone marrow, reproductive cells, and human embryos at the early development stages, as well as valuable breeds of animals, rare and endangered fish species. The foundations of a new direction "Extreme cryotherapy" were laid. The technology of cryoconservation and longterm preservation of plant materials - fruits, vegetables, cereals, and others - was developed.

When creating the ILTPE, Boris Ieremievich Verkin and Alexander Alexandrovich Galkin were likeminded people and friends. But soon it became clear that "it was difficult for two bears to live in one cave". Therefore, Alexander Alexandrovich decided to create a new independent institute. Owing to his talent as an organizer and his recognized image as a physicist, according to the resolution of the Presidium of the AS UkrSSR, as well as the authorities at that time, the Central Committee of the Communist Party of Ukraine and the Counsil of Ministers of the Ukrainian SSR, a Regional branch of the AS UkrSSR (including the Donetsk and Lugansk regions) was created. Academician A.A. Galkin was appointed the chairman of the Regional branch. Simultaneously, A.A. Galkin was appointed the director of a system- 
forming institution of the branch, the Donetsk Institute for Physics and Engineering of the AS UkrSSR (DonIPE). Later, the DonIPE was named after A.A. Galkin. In different years, the institute was headed by A.A. Galkin, N.M. Kovtun, and E.A. Zavadskii. At present, the director of the institute is V.N. Varyukhin.

An ambitious plan was proclaimed: "Let us transform Donetsk into a city of science!" The city and region government in every way favored the fastest development of the Institute. A team of talented physicists, which arrived from the ILTPE and was headed by A.A. Galkin, to a great extent facilitated the rapid formation of the Institute. A team of talented electronic engineers headed by G.G. Grinyov also arrived from the ILTPE and promoted the creation of the experimental design office of the Institute. At first, the departments, laboratories, and the cryogenic department were located at about ten addresses throughout the city. The employees also obtained temporary apartments. Simultaneously with the large-scale building of the Institute itself, the dwellings were also built for the employees. The construction of the Institute was visited by V.V. Shcherbytskyi, at that time the First Secretary of the Central Committee of the Communist Party of Ukraine. On his recommendation, the Donetsk regional committee of the Communist Party of Ukraine created a headquarters to control and coordinate the construction process.

Owing to the clear-sighted politics of Academician of the AS UkrSSR A.A. Galkin, the structure of the Institute was complex from the very beginning. It included departments dealing with fundamental researches; a cryogenic section with the nitrogen and helium liquefiers; an experimental production workshop with equipment providing the whole technological cycle of manufacturing complicated and scienceconsuming products (precision mechanics, electronic devices) and with a specialized department for fabricating vacuum and cryogenic facilities; and a special design bureau (SDB). On the basis of the latter, a special design and technology bureau (the SDTB of the A.A. Galkin DonIPE of the AS UkrSSR) was created later.

At the moment when the Institute was organized, its structure included 13 scientific units. The subjects of their researches were connected with the most challenging problems of the solid state physics. The skillful selection of a personnel and the strategi- cally correct choice of main scientific directions for the Institute at the stage of its creation stimulated its rapid development and the establishment as the largest academic scientific institution in the Donetsk region. Within a short time interval, the production of cryogenic liquids was mastered, which allowed the Institute to develop as a center of researches at low and ultra-low temperatures. Under the direction and with the participation of A.A. Galkin, the detector properties of superconductors were discovered for the first time, the kinetics of superconductivity destruction in high-frequency fields was studied, the crystallographic anisotropy of the superconducting energy gap was discovered and investigated, the technical application of superconductivity was developed, and cryomagnetic complexes on the basis of superconducting solenoids were created. In the last years of his life, the main attention of A.A. Galkin was focused on the development of high-pressure physics, in particular, its applied aspect. The results of this work became a scientific basis for a new technology of material processing, hydroextrusion. This technology was introduced into the industry for the non-waste formation of products with complicated profiles. The new technology made it possible to produce a superconducting stranded wire. In 1978, the Institute became the leading research institute of the USSR in this direction.

Complex studies of the matter under extreme conditions - low temperatures, high pressures, and strong magnetic fields - and the developments in nanotechnology became and still remain the scientific visiting card of the Institute, which brought it a worldwide recognition. The extension and deepening of Institute's research topics resulted in the emergence of a number of new independent scientific institutions important for the country. Among them, there are the Institute of Physico-Organic Chemistry and Coal Chemistry of the AS UkrSSR, the Scientific and Research Institute of Complex Automation of the Ministry of Industry and Communications of the USSR, the Special Design Bureau Luch of the Ministry of General Mechanical Engineering of the USSR specializing in solving the space exploration problems, the Institute of Physics of Mining Processes of the AS UkrSSR. In 1965, the Donetsk Computer Center of the AS UkrSSR was created (in 1970, it was transformed into the Institute of Applied Mathematics and Mechanics of the AS UkrSSR). 


\section{First Ukrainian Metal Cryostats and Their Evolution}

Among tools that are necessary to perform a low-temperature experiment, there are cryostats and complex cryogenic and cryomagnetic installations. Therefore, A.F. Prikhotko, B.I. Verkin, and A.A Galkin as experimentalists paid special attention to the scientific low-temperature instrument making, namely, cryostats. Therefore, let us consider their evolution in each of the institutes separately.

It should be noted that the first cryostats that the physicists worked with were made of glass. They possessed a number of shortcomings. In particular, they were fragile and unreliable in exploitation. Moreover, they could work with liquid nitrogen only. Therefore, it was necessary to create cryostates of a new type, which would be free of the mentioned shortcomings and could work reliably with various cryoagents. In order to implement the ideas of physicists-experimentalists into a metal construction and on the initiative of A.F. Prikhotko, a technical department was created at the experimental production workshop of the Institute of Physics of the AS UkrSSR. The workshop designers Borodina, Ryabchuk, and Brazhkin developed the design of cryostats from 1954 to 1968. The customers of cryostats included such scientists as A.F. Prikhotko, V.L. Broude, V.S. Medvedev, M.S. Brodyn, O.L. Fialkovskaya, L.S. Kremenchugskii, and others.

At that time, the available metal cryostats were of several types: nitrogen, nitrogen-paraffin, hydrogen, and helium. Most of them were nonseparable. The dimensions of the cryostats were very different: the outer diameter varied from 100 to $200 \mathrm{~mm}$, and the height from $500 \mathrm{~mm}$ to $1 \mathrm{~m}$ and higher. Hydrogen and helium cryostats had a nitrogen tank (a nitrogen isolating jacket), which completely surrounded the helium and hydrogen tanks.

In 1956 and 1957, there were created cryostats for optical measurements at the temperature of liquid hydrogen (V.L. Broude, V.S. Medvedev, and V.P. Babenko) based on the liquid-flowing method of temperature control (the so-called Swenson's method). They included a number of design solutions that found applications in further developments: the perfect vacuum sealing of glass and quartz windows, the nitrogen screen, and the cooled carbon cartridge. The liquid hydrogen temperature was $20 \mathrm{~K}$, and the cryoa- gent consumption was $0.5 \mathrm{l} / \mathrm{h}$. Furthermore, these were the first sectional cryostats. In addition, their outer housing was made of copper, and the cryostats themselves had a soldered construction. Therefore, if defects were available, the cryostats could be unsoldered to eliminate them. In other words, the cryostats with such a design were repairable. Later, there appeared a number of inserts into the cryostats, which enabled the spectral analysis of crystals in polarized light, crystal-optical measurements, spectral studies of substances under all-round compression conditions at a gas pressure of up to $200 \mathrm{~atm}$, measurements of the photocurrent spectral distribution, and research of crystal topography on the basis of a crystal spectrum to be done.

The inserts were introduced into the cryostat from above. The controls over the insertion mechanisms were arranged at the cryostat top. In order to avoid the contamination and loss of hydrogen or helium, when the insert was being introduced into the cryostat, the latter had a lock chamber at the top. The insert was first introduced into the lock chamber; then the inlet was closed, the chamber lock open, and the insert was moved into the cryostat by means of a rod. Due to the limited volume of the paper, we will not detail the improvements to the cryostat design. The history of the development of cryostat construction at the Institute of Physics of the AS UkrSSR is described in work [5] in more details.

For experimental needs, cryostats were required that would take the specific nature of researches into account and provide a thermal control over specimens in a temperature interval of $2-300 \mathrm{~K}$. In 1965, on the initiative of A.F. Prikhotko, a special designtechnology group headed by V.S. Medvedev was organized. Later, in 1990, it was reorganized into a laboratory of cryogenic technologies. The task of the group was to develop cryostats for physical experiments carried out at the Institute of Physics and at other institutes of the Academy of Sciences. The first positive results were obtained in the early 1970s.

The highest achievement of the creative and scientific work of the group was author's certificate USSR No. 436334, applied and registered in 1974 by a team of authors headed by V.S. Medvedev (the organization-applicant was the Institute of Physics, the Academy of Sciences of the Ukrainian SSR). It was a revolutionary invention, which opened a way to the creation of precision and economical thermoreg- 
ulated cryosystems. In essence, it was a patented method of high-precision temperature control in cryostats.

The first temperature regulators were composed of a number of standard devices produced by the Soviet industry, but with the inclusion of an original analog amplifier of the disbalance signal between the required and actual temperatures. In particular, a resistance bridge or a voltage comparator was used as a setting device depending on the type of the selected temperature sensor, a thermistor or a thermocouple, respectively. A recorder served as a registration unit.

Even despite this shortcoming, the obtained technical characteristics of cryosystems were so high (the temperature stabilization was not worse than $\pm 0.1 \mathrm{~K}$, and the liquid cryoagent consumption did not exceed $0.12 \mathrm{l} / \mathrm{h}$ ) that they attracted broad interest among the scientists-experimenters not only in the Soviet Union, but also in the states of the Council for $\mathrm{Mu}-$ tual Economic Assistance. The first customers from foreign countries were scientists from the Institute of Physics of the Academy of Sciences of Czechoslovakia (Prague) and the Humboldt University (Berlin, German Democratic Republic).

This success had to be enhanced by eliminating the set of executive devices, which created difficulties at the delivery and assembly of products. Therefore, there arose a problem to create a temperature controller that would be capable to independently control the temperature with a high accuracy. The physicist and electronic engineer V.V. Safronov, who joined the department headed by V.S. Medvedev in 1977, tackled this problem. The task of creating executive devices for regulating gas fluxes and elaborating a common design construction for the temperature regulator was solved by the designers of the A.G. Chmul group.

The work on the creation of temperature regulator resulted in the obtaining of two author's certificates USSR No. 1315960 and No. 1594504 in 19871990. Owing to their implementation, the developed cryosystems got a compact form: instead of a set of industrial devices, only one temperature regulator was used, which provided a high stability of the temperature and its indication during the exploitation. The popularity of fabricated cryosystems is confirmed by the number of devices supplied during 1987-1991 to various scientific institutions of the USSR: more than 150 items.
Three following factors - high-precision economical cryostats, modern temperature regulators, and a low total price of the fabricated cryosystems - allowed the Institute to enter the world market of cryogenic facilities. In 1995-2000, deliveries were made to Estonia (the Institute of Physics, Estonian Academy of Sciences, Tartu, 2 items), Czech Republic (the Institute of Physics, Prague, 2 items), Switzerland (the University of Zurich), Germany (the Institute of Radiochemistry, Mülheim an der Ruhr and the University of Regensburg, Marburg), France (Research Center CEDEX), the USA (the University of Montana), and Israel (the Solid State Institute, Haifa, 2 items). In 2002-2004, the cryosystems were supplied to Germany (the Technical University of Darmstadt, 2 items) and the USA (the University of Mississippi). In 2013, the cryosystem was supplied to the Institute of Physics of the Academy of Sciences of Slovakia (Bratislava).

It should be noted that, along with the work aimed at the "team survival" and earning funds for its development, the research work was also continued, although its intensity was not very high owing to the reasons indicated above. In particular, a universal thermocontrolled cryostat system was created in 2003. It can be used with practically any type of a coolant (except for $\mathrm{He}_{3}$ and its mixtures) and has a high-precision temperature control. In 2004, a cryostat system was created for an optical microscope with temperature control within an interval of 40$800 \mathrm{~K}$, which had no analogs in the world. Since 2013, for industrial needs, the laboratory has being developed and manufactured cryosystems for a thermocyclic processing of tools and machine components in a temperature interval from $-186^{\circ} \mathrm{C}$ to $+150^{\circ} \mathrm{C}$ in order to increase the period of their exploitation.

The developed solutions were implemented in cryostat systems manufactured at the Institute of Physics of the National Academy of Sciences of Ukraine (NASU) in Kyiv. The Kyiv cryostats with the acronym UTRECS (Unified ThermoRegulated Cryostat Systems) were awarded the gold and silver medals of the Exhibition of Economic Achievements of the USSR, and the gold medal of the International Leipzig Fair. In 2014, the laboratory team was awarded the B.I. Verkin Prize of the NASU. The UTRECS cryostats are successfully used at the scientific institutions of USA, France, Germany, Israel, Czech Republic, Poland, and other countries.

ISSN 2071-0194. Ukr. J. Phys. 2018. Vol. 63, No. 5 
The cryostats developed by Kharkiv designers for physical experiments were also oriented on the liquidflowing regulation principle, but the cryostat housing was fabricated from stainless steel, and it was all-welded, which resulted in the overweight of the construction and its bad maintainability. But this approach gave very good results and was reliable in the case of cryosystems with built-in superconducting solenoids. To eliminate the excess mass of steel, the flow-through method of cryostating was begun to be applied, and cryostats with small dimensions were started to be fabricated. The "thing" of Kharkiv developers was dissolution cryostats allowing millikelvin temperatures to be reached and having no analogs in Ukraine and in the CIS countries.

A detailed information on the cryogenic developments of specialists from the ILTPE can be found in work [4].

The works of Kharkiv scientists and designers were awarded the state awards of both the Soviet Union and Ukraine. They have the highest awards at both the domestic and international exhibitions of scientific and technical achievements. Because of the limited volume of the paper, the authors cannot give full information about the design of cryostats fabricated at the ILTPE, because this information would require at least a separate book.

At the SDTB of the A.A. Galkin DonIPE of the NASU, four departments with a staff of about 100 people were engaged in the cryogenic instrument making. Each of the department was a complex unit able to solve problems in the corresponding domain. These were (i) the department of superconducting magnetic systems (the head of the department was A.Ya. Laptienko, the head of the sector was N.V. Taryanik; the department dealt with the development of methods for calculating superconducting magnetic systems with high-uniform fields and research installations on their basis, special-purpose systems, systems for magnetic-levitation trains, and systems for the magnetic separation of a dust-coal fuel for thermal power plants); (ii) the department of electronic devices (the head of the department was I.A. Kulik; the department dealt with current sources for feeding the solenoids in superconducting magnetic systems and installations for testing the parameters of short superconductor specimens); (iii) the department of equipment (the heads of the department were, in turn, L.G. Oranskii, V.N. Krymov, and V.N. Solenyi; the department studied the paramagnetic resonance in the two-millimeter range); and (iv) the department of cryogenic instrument making (the head of the department was A.G. Demishev; the department developed the calculation methods, as well as cryostats and complex cryogenic installations with a controllable temperature).

Unfortunately, the current situation does not allow us to correctly illuminate the developments of all SDTB departments dealing with the cryogenic instrument making and having significant success in this direction. Therefore, we mainly describe the works of the department of cryogenic instrument making concerning the development, creation, and implementation of both bath cryostats and small-sized continuous-flow ones, as well as complex automated installations with controlled temperature, including superconducting solenoids for researches in the magnetic field. The work was carried out to satisfy the needs of the Institute and separate orders of other institutions and enterprises However, the main activity was aimed at solving the most complicated problems of leading enterprises and institutions in the electronic, aviation, and space-rocket industries. The available scientific and engineering potential of the leading talented developers (the head of the design sector D.P. Pelykh and the leading engineer-designer V.E. Shcherbina, the head of the experimental sector V.Z. Suplin and the leading engineer A.K. Shirkov, the head of the electronic sector N.I. Bondarenko and the leading engineer G.I. Petushkov) and the production capabilities of the Experimental production workshop of the DonIPE provided an opportunity for the department to occupy a prominent place among the leading developers and creators of complicated science-consuming devices and complex installations and to implement them at the leading defense enterprises and institutions. The development works were carried out on the basis of the dissertation work of A.G. Demishev, one of the authors of this paper, "Research of heat transfer in the cryostat neck, the calculation technique, and the development of cryostats and complex cryogenic systems".

For instance, one of the first was the development of cryostats of the series "KG" (the series included four cryostats: KG-55, KG-100, KG-150, and KG$200)$, which obtained a wide application and became a basis for the creation of cryogenic research installations. At the experimental production workshop of 
the DonIPE and at the base production workshop of the Scientific Research Institute "Saturn" (Kyiv) in the town of Glukhov, over 150 items of those cryostats were manufactured and supplied to enterprises and institutes of the Soviet Union. The description of cryostats of the KG series was included into the "Handbook on the physical and technical bases of cryogenics" edited by Prof. M.P. Malkov (Energoatomizdat, Moscow, 1985).

In the midst of the "Star Wars" initiated by the US President R. Reagan, the decision-making authority of the USSR adopted a response program of works in the electronic, aviation, and space-rocket industries. The SDTB of the DonIPE, being engaged in the implementation of the cryogenic part of the program, fulfilled a number of projects aimed at the solution of three most urgent research problems under the conditions of industrial enterprises, metrological certification and selection of the products intended for the operation under cryogenic temperatures: electronic equipment and preamplifiers on their basis, optical filters, and ultrasensitive photodetectors. Those elaborations were used as a basis for the development, fabrication, and supply of automated installations for the metrological certification of the parameters of electronic equipment and preamplifiers on their basis at enterprises; in particular, a series of cryostats "Cryostat Cryo-CTF" with the standard size and a series "Cryostat Cryo-CTR", as well as and installations on their basis for the metrological certification of the characteristics of optical filters. The top point of those developments was cryostats of the series "CRYOSTAT CRYO-F-PHR" for the metrological certification of the parameters of filters and ultrasensitive photodetectors within the period of a single experiment.

Along with this achievement, a number of unique, in the Soviet Union, complex automated installations for studying the properties of materials within the temperature interval from room temperature to helium ones were created:

- three types of cryomagnetic installations for neutron diffraction studies were installed at the physical reactor at the Beloyarsk NPP (the Sverdlovsk region, Russia);

- two types of cryomagnetic installations for studying the effect of electron irradiation on materials were installed at linear electron accelerators at the Institutes of Metal in Moscow and Sverdlovsk to study the transmittance, specular reflection, and total indicatrix of filter and mirror scattering at probing-beam incident angles from 0 to $90^{\circ}$;

- a cryomagnetic installation with a long service life for the NMR spectrometer.

Cryomagnetic installations created at the department were equipped with superconducting solenoids designed and developed at the department of superconducting magnetic systems. Power sources for solenoids for currents of 75,100 , and 200 A were created by the department of electronics. Later, the department of electronics reconstructed those sources, so that they could be governed by a computer. The current/field sweep can be selected according to operator's commands or by a software code. The department developed, and the SDTB fabricated electronic meters of the helium level on the basis of a superconducting filament with direct or indirect heating. Electronic instruments for the temperature measurement and control with an integrated microprocessor, as well as a software for their operation, were created by the electronic sector of the department. All that significantly simplified the design of cryostats and the experimental technique and made it possible to create completely automated complex cryogenic and cryomagnetic installations that enabled the experiments to be controlled by a "top-level" computer program.

A special place is occupied by the development of a method for simulating permafrost conditions of the Far North for long buried structures (large-diameter gas pipes). The elaboration was made together with the Gas Institute (Moscow, Russia) and protected by author's invention certificate. The development was aimed at studying the causes of catastrophic multikilometer explosive destructions of gas pipelines in the Far North regions and making proposals for their prevention. The joint, together with the Gas Institute, project on the verification of the proposed theory concerning the gas-dynamic character of the large-scale destruction of pipes and the method of simulating permafrost conditions under testing-area conditions was announced a winner of the All-Union competition. Under contracts with the firms from Japan, Italy, and Germany, joint tests of the pipes $1420 \mathrm{~mm}$ in diameter fabricated by those firms were performed at a pressure of $100 \mathrm{~atm}$. The test results completely confirmed the suggested proposals, and the solutions were approved by all participating sides. Later, the 
State Committee on Inventions and Discoveries, with regard for the positive juridical and practical experience of cooperation with foreign firms concerning the selling of only the right to use the invention on our territory, held a number of training seminars over the country.

The developed cryostats and complex automated installations were repeatedly presented at international conferences and exhibitions in the USSR and abroad: in Bulgaria, Czechoslovakia, Italy, Romania, and Germany.

The following developments were awarded by the Main Committee of the VDNKh of the USSR:

- a gold medal for the complex of cryogenic systems with a controllable temperature for neutron diffraction studies;

- a bronze medal for the small-sized cryostat with a continuous flow and controllable temperature for optical investigations;

- a bronze medal for cryostats of the unified KG series (the SDTB of the DonIPE of the NASU was awarded the honorary diploma);

- a silver medal for the development of physical basis for the creation of a complex of cryogenic automated installations with a controlled temperature for scientific researches;

- the DonIPE of the AS UkrSSR was awarded a diploma of the 2nd degree for the development and creation of a complex of cryogenic units intended for studying the optical properties of materials.

The main committee of the Exhibition of achievements in the national economy of the Ukrainian SSR awarded the SDTB with a first-degree diploma and A.G. Demishev with a breastplate for the development of a cryostat for a high-resolution NMR radio spectrometer.

Detailed information on cryogenic developments can be found in work [7]. The most important works of the Institute and the SDTB concerning the cryostats and solenoids, including the full-scale specimens of cryostats of the KP, KPO, and FPU series, are exhibited at the museum of Institute's history.

\section{Final Remarks}

It should be noted that, due to the decay of the USSR and the Union of Mutual Economic Assistance, as well as the difficult political and economic situation in Ukraine, the established economic links were destroyed, and the demand for scientific and technical products, including cryogenic ones, drastically diminished. The SDTB of the DonIPE failed to complete a number of important works, which were at the final stage: a cryogenic system on the basis of microcryogenic closed-cycle machines, a cryomagnetic complex intended for cleaning a dust-coal fuel for thermal power plants, a cryogenic unit for a receiver in a space telescope, a cryogenic supply system for a superconducting gyroscope at nuclear submarines. A similar situation also arose at the SDTB of the ILTPE.

But even in this difficult situation, the administration of the institutes managed to preserve the main staff of developers of cryogenic equipment. They are optimistic about the future and hope for the recovery, similarly to how the UPTI, which was destroyed during World War II, was recovered and developed after the war. A belief in the best is confirmed by the fact that specialists in cryogenic technology are continued to be trained in Ukraine: in Kharkiv (V.N. Karazin National University of Kharkiv) and in Odessa (V.S. Martynovsky Institute of Refrigeration, Cryotechnologies, and Ecoenergetics of the Odessa National Academy of Food Technologies) [8,9].

The authors are grateful to the employees of the ILTPE of the NASU V.A. Lototskaya and S.L. Bondarenko for the information, useful advice, and assistance in writing this article.

1. https://odnarodyna.org/content/fizik-eksperimentatorivan-obreimov.

2. http://www.ilt.kharkov.ua/verkin/download/kniga.pdf

3. http://www.iop.kiev.ua/ val/cnews2/print.php?id $=179$

4. http://www.peoples.ru/science/physics/alexandr_galkin/.

5. http://www.iop.kiev.ua/ cryo/about history.php.

6. http://ftint50.ilt.kharkov.ua/pdf/ch2 ${ }^{-} 12$.pdf.

7. http://www.donfti.ru/main/razrabotki-instituta/.

8. https://www.onaft.edu.ua/ru/.

9. http://www.irce.onaft.edu.ua/.

Translated from Ukrainian by O.I. Voitenko

І.П. Жарков, А.Г. Демішев

ПРО ІСТОРІЮ КРІОГЕННОГО

ПРИЛАДОБУДУВАННЯ В УКРАЇНІ

$\mathrm{P}$ е $з$ ю м е

Коротко описано історію кріогенного приладобудування в Україні. 